\title{
Microbial Community Shifts Reflect Losses of Native Soil Carbon with Pyrogenic and Fresh Organic Matter Additions and Are Greatest in Low-Carbon Soils
}

\author{
(D) Thea Whitman, ${ }^{\mathrm{a}, \mathrm{b}}$ Silene DeCiucies, ${ }^{\mathrm{b}}$ Kelly Hanley, ${ }^{\mathrm{b}}$ Akio Enders, ${ }^{\mathrm{b}}$ (D) Jamie Woolet, ${ }^{\mathrm{a}}$ (D) Johannes Lehmann ${ }^{\mathrm{b}, \mathrm{c}}$ \\ aDepartment of Soil Science, University of Wisconsin—Madison, Madison, Wisconsin, USA \\ bSoil and Crop Sciences, School of Integrative Plant Science, Cornell University, Ithaca, New York, USA \\ cAtkinson Center for a Sustainable Future, Cornell University, Ithaca, New York, USA
}

ABSTRACT Soil organic carbon (SOC) plays an important role in regulating global climate change, carbon and nutrient cycling in soils, and soil moisture. Organic matter (OM) additions to soils can affect the rate at which SOC is mineralized by microbes, with potentially important effects on SOC stocks. Understanding how pyrogenic organic matter (PyOM) affects the cycling of native SOC (nSOC) and the soil microbes responsible for these effects is important for fire-affected ecosystems as well as for biochar-amended systems. We used an incubation trial with five different soils from National Ecological Observatory Network sites across the United States and ${ }^{13} \mathrm{C}$-labeled $350^{\circ} \mathrm{C}$ corn stover PyOM and fresh corn stover OM to trace nSOC-derived $\mathrm{CO}_{2}$ emissions with and without PyOM and $\mathrm{OM}$ amendments. We used high-throughput sequencing of rRNA genes to characterize bacterial, archaeal, and fungal communities and their responses to PyOM and $\mathrm{OM}$ in soils that were previously stored at $-80^{\circ} \mathrm{C}$. We found that the effects of amendments on nSOC-derived $\mathrm{CO}_{2}$ reflected the unamended soil $\mathrm{C}$ status, where relative increases in $\mathrm{C}$ mineralization were greatest in low- $\mathrm{C}$ soils. OM additions produced much greater effects on nSOC- $\mathrm{CO}_{2}$ emissions than PyOM additions. Furthermore, the magnitude of the microbial community composition change mirrored the magnitude of increases in $\mathrm{nSOC}-\mathrm{CO}_{2}$, indicating that a specific subset of microbes was likely responsible for the observed changes in $\mathrm{nSOC}$ mineralization. However, PyOM responders differed across soils and did not necessarily reflect a common "charosphere." Overall, this study suggests that soils that already have low SOC may be particularly vulnerable to short-term increases in SOC loss with OM or PyOM additions.

IMPORTANCE Soil organic matter (SOM) has an important role in global climate change, carbon and nutrient cycling in soils, and soil moisture dynamics. Understanding the processes that affect SOM stocks is important for managing these functions. Recently, understanding how fire-affected organic matter (or "pyrogenic" organic matter [PyOM]) affects existing SOM stocks has become increasingly important, due to both changing fire regimes and interest in "biochar," pyrogenic organic matter that is produced intentionally for carbon management or as an agricultural soil amendment. We found that soils with less SOM were more prone to increased losses with PyOM (and fresh organic matter) additions and that soil microbial communities changed more in soils that also had greater SOM losses with PyOM additions. This suggests that soils that already have low SOM content may be particularly vulnerable to short-term increases in SOM loss and that a subset of the soil microbial community is likely responsible for these effects.

KEYWORDS ${ }^{13} \mathrm{C}$, NEON, biochar, decomposition, mineralization, positive priming, soil, stable isotopes

Citation Whitman T, DeCiucies S, Hanley K, Enders A, Woolet J, Lehmann J. 2021. Microbial community shifts reflect losses of native soil carbon with pyrogenic and fresh organic matter additions and are greatest in lowcarbon soils. Appl Environ Microbiol 87:e255520. https://doi.org/10.1128/AEM.02555-20. Editor Rebecca E. Parales, University of California, Davis

Copyright $\odot 2021$ Whitman et al. This is an open-access article distributed under the terms of the Creative Commons Attribution 4.0 International license. Address correspondence to Thea Whitman, twhitman@wisc.edu.

Received 19 October 2020 Accepted 21 January 2021 Accepted manuscript posted online 29 January 2021

Published 26 March 2021 
oil organic matter (SOM) supports a wealth of benefits in soil systems. This includes providing organic nutrients, binding toxic compounds, increasing the soil waterholding capacity, and storing soil organic carbon (SOC). Globally, soils hold large stocks of carbon (C), twice the amount of $C$ held in living biomass or in the atmosphere (1). Understanding the processes that control the stocks and fluxes of $C$ in and out of the soils is thus essential for mitigating climate change as well as for sustainable agricultural management (2). Recently, the importance of understanding the role of fireaffected organic matter (or pyrogenic organic matter [PyOM], sensu Zimmerman and Mitra [3]) in contributing to SOC stocks has become increasingly salient. PyOM can make up large portions of soil carbon stocks, particularly in fire-affected ecosystems (4), where it can represent over $60 \%$ of the total SOC (5). Its persistence in soils has led to interest in its role in offsetting the climate impacts of natural wildfires (4) as well as the possibility of its intentional production for the stabilization of organic matter (OM), in which case it is often referred to as "biochar" $(6,7)$. However, in order to quantify its net effect on $C$ stocks and fluxes, it is essential to understand not only the persistence of pyrogenic $\mathrm{C}(\mathrm{PyC})$ itself but also its effect on the native SOC (nSOC) present before PyC additions.

After interest was sparked in the potential of PyC for climate change mitigation just over a decade ago, alarm bells were sounded about the possibility of its addition to soils resulting in an increased loss of nSOC and increased $\mathrm{CO}_{2}$ emissions (8-10). These observations ignited a flurry of research into the potential interactions between added PyC and nSOC. This research was important because if PyOM additions are to be used for climate change mitigation, the added PyC must not be offset by increased nSOC losses. Initial investigations revealed a range of responses, spanning from large increases in $\mathrm{nSOC}$ mineralization to large decreases in SOC mineralization with PyOM additions (11-13). (Although the term "priming" [14] is widely used to describe this phenomenon, due to broad interpretations of the term [15], we refer to "increased or decreased mineralization"; even though less concise, this method- and process-agnostic term will help ensure clarity and avoid prior expectations of what the term priming implies.) Research over the past decade has progressed beyond the observation of the phenomenon to systematic investigations of the mechanisms underlying these interactions (16-18), while the conclusions from meta-analyses have strengthened as the total number of studies of PyOM-SOC interactions has steadily increased (19-22).

The above-cited meta-analyses provide a robust overview of recent advances in the literature. Briefly, the current understanding of mechanisms underlying the interactive effects of PyOM additions on SOC mineralization includes the following observations (19-22). (i) In general, when changes in mineralization occur, net increases in nSOC mineralization tend to be limited to the earlier stages of incubations or field studies, while net decreases in nSOC mineralization often emerge later. (ii) It is essential to consider the specific properties of PyOM and the soil to which it is applied in tandem. Properties such as $\mathrm{pH}$, total $\mathrm{nSOC}$ content, nutrient status, and texture or particle size are important determining factors of the net $\mathrm{C}$ effects of PyOM additions on nSOC. (iii) Specific researcher-determined conditions of the study can significantly affect the response variables of interest. This is particularly true for moisture and duration of the experiment. Although the above-mentioned factors make it challenging to collectively develop a predictive understanding of interactions between SOC and PyOM mineralization, it is important to design experiments explicitly to test for and quantify the relative importance of specific mechanisms. In this spirit, in this study, we sought to investigate short-term increases in SOC mineralization with PyOM amendments.

Although numerous studies have now observed net decreases in SOC mineralization with PyOM amendments over the long term, characterization of the mechanisms that underpin both of these phenomena will help us develop appropriate models for predicting long-term effects into the future $(23,24)$. For example, in a $C$ cycling model designed to predict the long-term effects of PyOM on $\mathrm{C}$ stocks (23), the assumption is that the dominant mechanism of decreased SOC mineralization is sorption of SOC by 
the PyOM, which is represented in the model by decreasing the fraction of SOC that is partitioned to the more rapidly cycling pool. However, the assumption for increased SOC mineralization is that the dominant mechanism is increased microbial activity, which is represented in the model by increasing the rate at which $\mathrm{nSOC}$ is mineralized. These assumptions create a model structure that helps drive the model's predictions of long-term net decreases in $\mathrm{nSOC}$ mineralization with PyOM additions. Although increases in $\mathrm{nSOC}$ mineralization rates after PyOM additions seem to be limited to short and medium (<2-year) timelines $(21,22)$, we wanted to investigate these shortterm effects since they pose the greatest risk of unintended consequences for nSOC stocks during intentional PyOM additions as biochar for $\mathrm{C}$ management or for increased nSOC losses due to PyOM inputs after wildfires.

Commonly proposed mechanisms for short-term increases in nSOC mineralization with PyOM additions can be broadly grouped into two categories: (i) cometabolism, where easily mineralizable PyOM fractions increase microbial activity, resulting in the additional decomposition of SOC, and (ii) stimulation, where PyOM additions may result in changes to the soil chemical or physical environment that generally favor increased microbial activity, such as more optimal $\mathrm{pH}$, nutrient, oxygen, or water conditions $(19,20)$. In addition, community composition shifts could also help explain these phenomena (25). It is possible that PyOM additions could induce changes to the microbial community composition that shift the community toward taxa that favor different sources of organic matter or process organic matter differently, e.g., organisms with different carbon use efficiencies (CUEs) (18). Finally, researchers often distinguish these effects from "apparent priming," when total $\mathrm{CO}_{2}$ emissions from soil increase but this increase is not accompanied by increases in nSOC losses (15). Rather, the increase is attributed to an increased turnover of soil microbial biomass. While the effects included under stimulation are essential to understand in order to predict SOC fluxes, they are, mechanistically, comparably straightforward: researchers have long studied the effects of changing moisture or oxygen on SOC fluxes. If we are able to quantify the degree to which PyOM additions to soil change these properties, we will be on our way to predicting their effects on nSOC cycling. However, the effects included under cometabolism and community composition shifts are generally less well characterized, and it is these mechanisms that we specifically sought to investigate in this study.

While research into the mechanisms behind changes in SOC mineralization with PyOM additions has grown substantially over the last decade, our understanding of which microbes respond to PyOM additions, and the reasons for their response, has somewhat lagged behind, particularly for fungi. As an exception to this, a recent investigation by $\mathrm{Yu}$ et al. into the effects of PyOM on SOC mineralization included an assessment of bacteria and fungi using high-throughput sequencing, through which they identified that the relative abundances of the fungal classes Sordariomycetes and Tremellomycetes were significantly positively correlated with increases in SOC mineralization after 40 days of incubation (26). In our recent review of PyOM effects on soil bacterial communities (27), we reanalyzed papers published before 2018 that had publicly accessible data and used Illumina high-throughput sequencing of the 16S rRNA gene to characterize soil bacterial communities $(25,28-32)$. Using the same approach to reanalyze all data sets, we found the following: (i) although most communities were significantly altered by the addition of PyOM, rather than creating a "charosphere"dominated community $(33,34)$, PyOM-amended soil bacterial communities resembled their corresponding unamended soil communities more closely than they resembled different soils that had also been amended with PyOM; (ii) phylum-level responses to PyOM additions were not consistent across different soil and PyOM combinations (i.e., the taxonomic level is generally too broad to make meaningful conclusions about soil bacterial responses to PyOM); and (iii) a small number of taxa were identified as being PyOM responders in more than one study, most of which came from the classes Actinobacteria, Alphaproteobacteria, and Betaproteobacteria (27). Based on these findings, we suggest that the field is still too nascent to make broad generalizations about 
TABLE 1 Studied soils and their properties

\begin{tabular}{|c|c|c|c|c|c|c|c|c|}
\hline Source location & Soil type & $\begin{array}{l}\text { C concn } \\
(\%)\end{array}$ & $\begin{array}{l}N \text { concn } \\
(\%)\end{array}$ & $\begin{array}{l}\text { Ca concn } \\
\left(\mathrm{mg} \mathrm{kg}^{-1}\right)\end{array}$ & $\begin{array}{l}\text { Mg concn } \\
\left(\mathrm{mg} \mathrm{kg}^{-1}\right)\end{array}$ & $\begin{array}{l}\text { Na concn } \\
\left(\mathrm{mg} \mathrm{kg}^{-1}\right)\end{array}$ & $\begin{array}{l}\text { K concn } \\
\left(\mathrm{mg} \mathrm{kg}^{-1}\right)\end{array}$ & $\mathrm{pH}$ \\
\hline Laupahoehoe, $\mathrm{HI}$ & Typic Hydrudand & 33.1 & 2.0 & 492 & 137 & 29 & 86 & 5.0 \\
\hline Caribou Creek-Poker Flats, AK & Pergelic Cryaquept & 9.4 & 0.4 & 540 & 68 & 16 & 20 & 5.0 \\
\hline Onaqui, UT & Xeric Haplocalcid & 2.6 & 0.1 & 5,619 & 245 & 28 & 511 & 8.3 \\
\hline Ordway-Swisher Biological Station, FL & Lamellic Quartzipsamment & 0.5 & 0.02 & 77 & 14 & 11 & 8 & 5.2 \\
\hline
\end{tabular}

any kind of consistent effect of PyOM on microbial communities and hope that continuing to blend functional measurements with microbial response data will help to identify which specific microbes might be responsible for changes in nSOC mineralization with PyOM additions while also generally increasing our understanding of which microbes respond to PyOM additions and why.

In this study, we had two research questions, with alternate hypotheses for each. Our first question was, are soils with less SOC more prone to stimulation by PyOM additions? Our primary hypothesis was that soils with less nSOC are more likely to experience increased mineralization with PyOM additions via cometabolism. Our alternate hypothesis rationalized the opposite: soils with less $\mathrm{nSOC}$ may be less likely to experience increased short-term mineralization with PyOM additions. This could occur if the microbial communities were limited by mineral nutrients. If PyOM additions alleviated this constraint via stimulation, microbial communities in soils with more mineralizable OC might be better able to take advantage of this subsidy. Our second question was, do soil microbial communities reflect changes in nSOC mineralization with PyOM additions? Our primary hypothesis was that there would be larger changes to the microbial community (larger Bray-Curtis dissimilarities between amended and unamended soils) in the soils where PyOM additions increased nSOC mineralization, while microbial communities in soils that did not experience increased nSOC mineralization would not change as much (smaller Bray-Curtis dissimilarities between amended and unamended soils). The rationale was that groups of microbes that respond positively to PyOM additions may be the same groups that are responsible for increased nSOC mineralization with PyOM additions, so a stronger shift toward these groups may accompany a stronger effect on nSOC mineralization. Our first alternate hypothesis was that PyOM might change microbial communities similarly in all soils: if PyOM additions had a very strong effect on the microbial community composition, creating a consistent charosphere community, dissimilarities between amended and unamended soils across soil types might not be statistically significant. Our second alternate hypothesis was that we might not see significantly different communities at all with PyOM additions. Although previous studies have seen significant changes to microbial communities with PyOM additions (27), these studies have often added extremely large amounts of PyOM. When applied at environmentally relevant rates, while PyOM additions may provide an additional $\mathrm{C}$ source, it may be relatively small in comparison to the available $\mathrm{nSOC}$, and any effects of PyOM additions on the soil water-holding capacity, $\mathrm{pH}$, or nutrient availability may not be large enough to significantly alter the soil microbial community composition from the unamended soil communities.

\section{RESULTS}

We incubated five contrasting soils with a range of SOC stocks from sites across the United States (Table 1) that had previously been stored at $-80^{\circ} \mathrm{C}$, adding ${ }^{13} \mathrm{C}$-labeled corn stover ("OM"), PyOM produced at $350^{\circ} \mathrm{C}$ from the same corn stover ("PyOM"), or no additions ("soil"). We monitored $\mathrm{CO}_{2}$ fluxes over 4 weeks and used stable isotope partitioning to separate $\mathrm{CO}_{2}$ emissions into SOC- and amendment-derived pools. We characterized the microbial (bacterial/archaeal and fungal) communities after $24 \mathrm{~h}$, 10 days, and 26 days using rRNA gene sequencing ( $16 \mathrm{~S}$ and internal transcribed spacer 2 [ITS2]) as they rebounded from freezing storage and responded to amendments. 

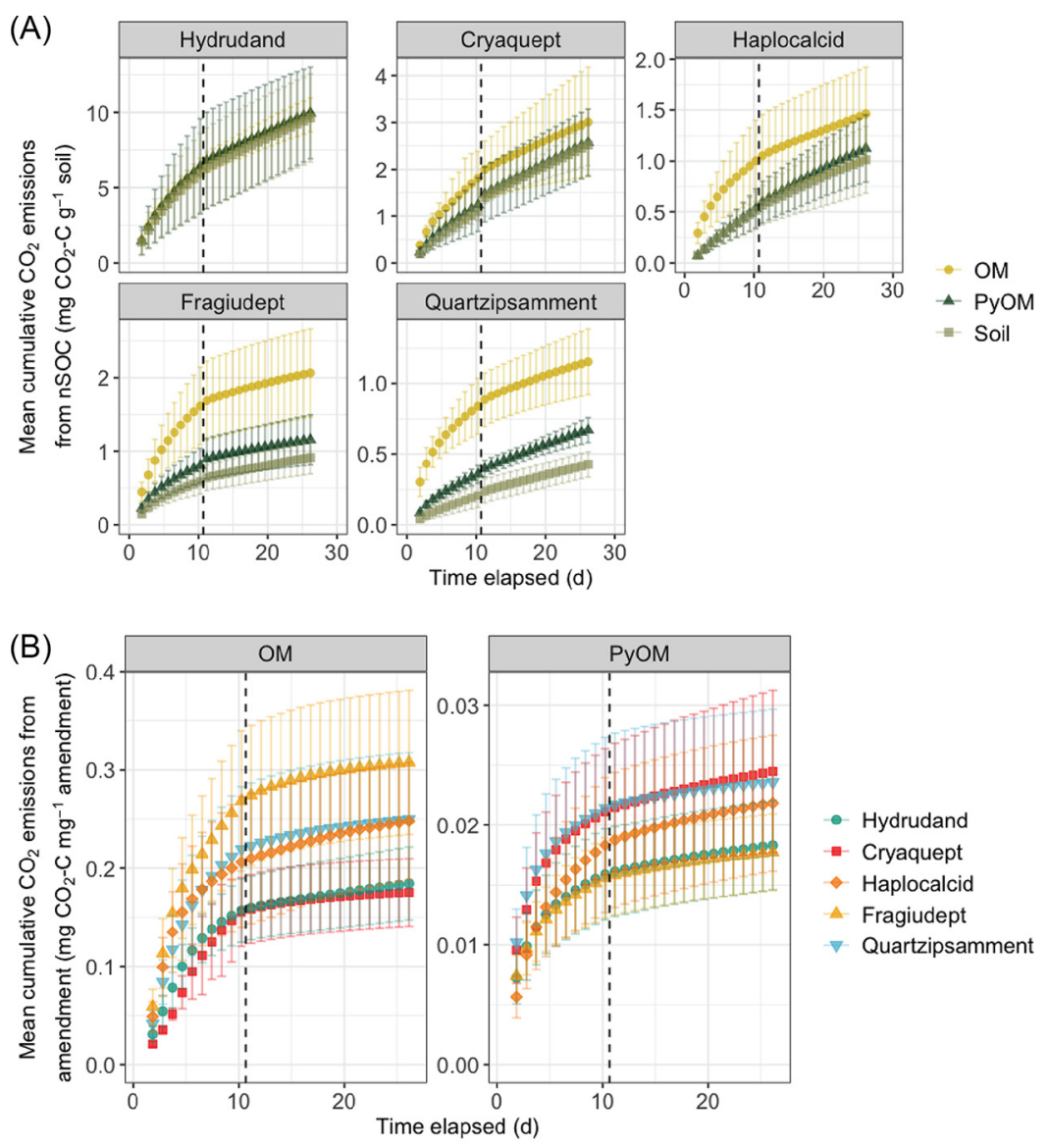

FIG 1 (A) Mean cumulative nSOC-derived $\mathrm{CO}_{2}$ emissions over time for each soil, with organic matter (OM) additions, pyrogenic organic matter (PyOM) additions, or no additions (Soil). Error bars represent \pm 1.96 standard errors (SE) (95\% confidence intervals). The dashed lines indicate the sampling point for midincubation harvests $(n=4)$. Note the different scales on the $y$ axes. (B) Mean cumulative amendment-derived $\mathrm{CO}_{2}$ emissions over time. Error bars represent $\pm 1.96 \mathrm{SE}$ (95\% confidence intervals). The dashed lines indicate the sampling points for midincubation harvests $(n=4)$. Note the different scales on the $y$ axes.

$\mathrm{nSOC}$-derived $\mathrm{CO}_{2}$ emissions were highest in the soils with the most total $\mathrm{SOC}$ (the Hydrudand and Cryaquept) and lowest in the soils with less total SOC (the Haplocalcid, Fragiudept, and Quartzipsamment) (Fig. 1). PyOM additions increased cumulative nSOC-derived $\mathrm{CO}_{2}$ emissions by $55 \%$ for the Quartzipsamment soil (Florida) only, while $\mathrm{OM}$ additions increased cumulative nSOC-derived $\mathrm{CO}_{2}$ emissions by $44 \%$ for the Haplocalcid (Utah), by $126 \%$ for the Fragiudept (New York), and by $170 \%$ for the Quartzipsamment (Florida) soils (Fig. 1 and 2). These effects were generally largest earlier in the incubation periods, although the significant effects persisted throughout the full 26 days for the Quartzipsamment.

The greatest changes in soil community composition (highest Bray-Curtis dissimilarity from unamended soil) upon amendment with PyOM or OM were associated with the greatest increases in nSOC-derived $\mathrm{CO}_{2}$ emissions (Fig. 3). For the full data set, bacterial and fungal community compositions were both significantly affected by soil type, days of incubation, amendment, and interactions between soil type and day and between soil type and amendment $(P<0.001$ for all effects by permutational multivariate analysis of variance [PERMANOVA]) (see Tables S4 and S5 and Fig. S1 and S2 in the supplemental material). Although our goal was not to determine the underlying causes of differences between communities in the unamended soils, all tested soil properties, $\mathrm{pH}$, cation exchange capacity (CEC), $\mathrm{Ca}, \mathrm{Mg}, \mathrm{Na}, \mathrm{K}$, total $\mathrm{C}$, and total $\mathrm{N}$, were significantly correlated $(P<0.05$ by PERMANOVA) with community composition for the $16 \mathrm{~S}$ 

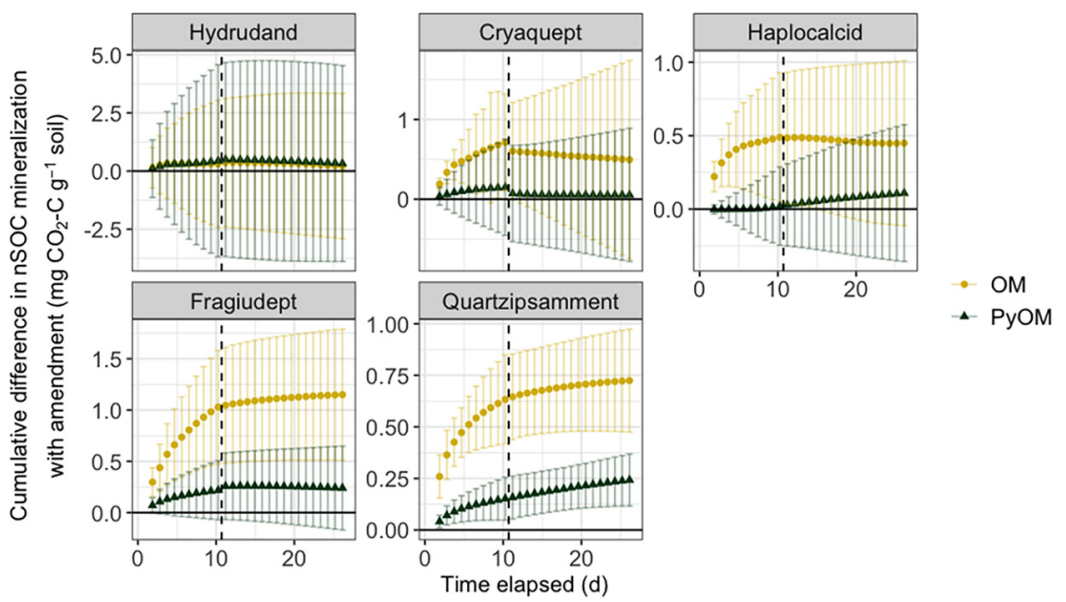

FIG 2 Mean cumulative difference in nSOC-derived $\mathrm{CO}_{2}$ emissions in amended soils compared to unamended soil over time for each soil, with organic matter (OM) additions and pyrogenic organic matter (PyOM) additions. Error bars represent $\pm 1.96 \mathrm{SE}$ (95\% confidence intervals), where nonoverlapping bars indicate significant differences. The dashed lines indicate the sampling points for midincubation harvests $(n=4)$. Note the different scales on the $y$ axes.

and the ITS2 data sets (Tables S6 and S7). For bacteria and archaea, when the soils were analyzed individually (Fig. 4A), days of incubation and amendment were both significant predictors of bacterial community composition $(P<0.02$ by PERMANOVA), except for the Hydrudand, where only days of incubation were significant (Table S5). The effects of amendments on bacterial community composition were least pronounced in the Hydrudand from Hawaii and the Cryaquept from Alaska and most pronounced for the Quartzipsamment from Florida (Table S8). For the fungi, when the soils were analyzed individually (Fig. 4B), amendment was a significant predictor of fungal community composition for all soils except the Cryaquept $(P<0.007$ by PERMANOVA), and days of incubation were significant for the Hydrudand, Cryaquept, and Fragiudept ( $P<0.03$ by PERMANOVA) (Table S9). The effects of amendments on fungal community composition were most pronounced in the Fragiudept from New York (Table S9).

Across all soils, we identified 258 16S operational taxonomic units (OTUs) that responded positively to OM amendments and $16216 \mathrm{~S}$ OTUs that responded positively to PyOM amendments (Fig. 5; Table S10). Only three ITS2 OTUs, Spizellomyces in the
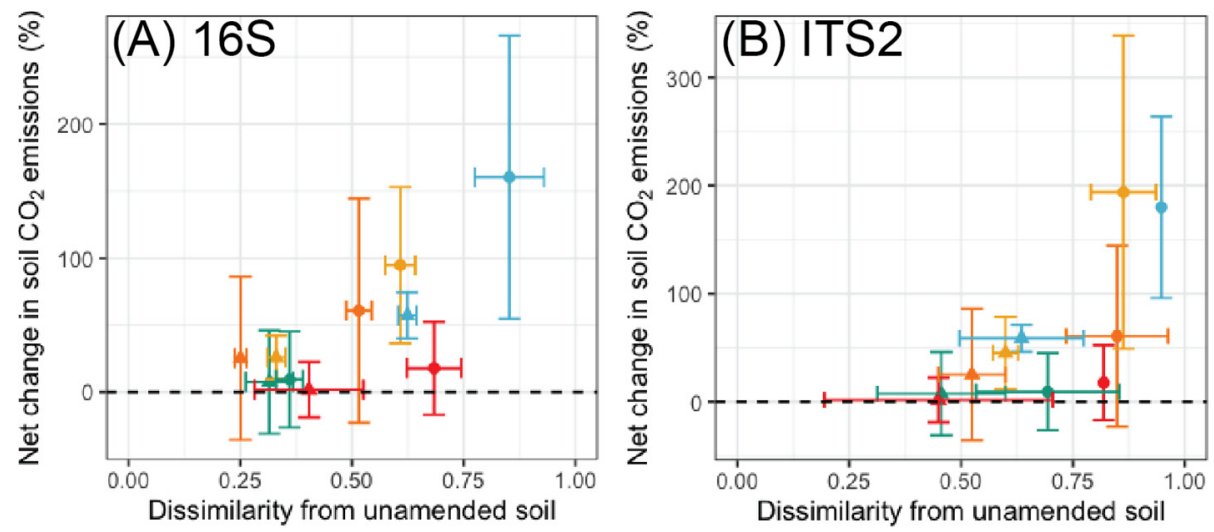

Amendment

- $\mathrm{OM}$

$\triangle$ PyOM

Soil Type

$\rightarrow$ Hydrudand

$\rightarrow$ Cryaquept

$\rightarrow$ Haplocalcid

$\multimap$ Fragiudept

$\rightarrow$ Quartzipsamment

FIG 3 Net change in soil-derived $\mathrm{CO}_{2}$ emissions (percent) versus Bray-Curtis dissimilarity on Hellinger-transformed abundances from unamended soil for different previously frozen soils and amendments at the final time point (day 26). Error bars represent \pm 1.96 SE (95\% confidence intervals). (A) Bacteria and Archaea (16S) $(n=4$, except for Quartzipsamment, where $n=3)$. (B) Fungi (ITS2) $(n=4)$. 

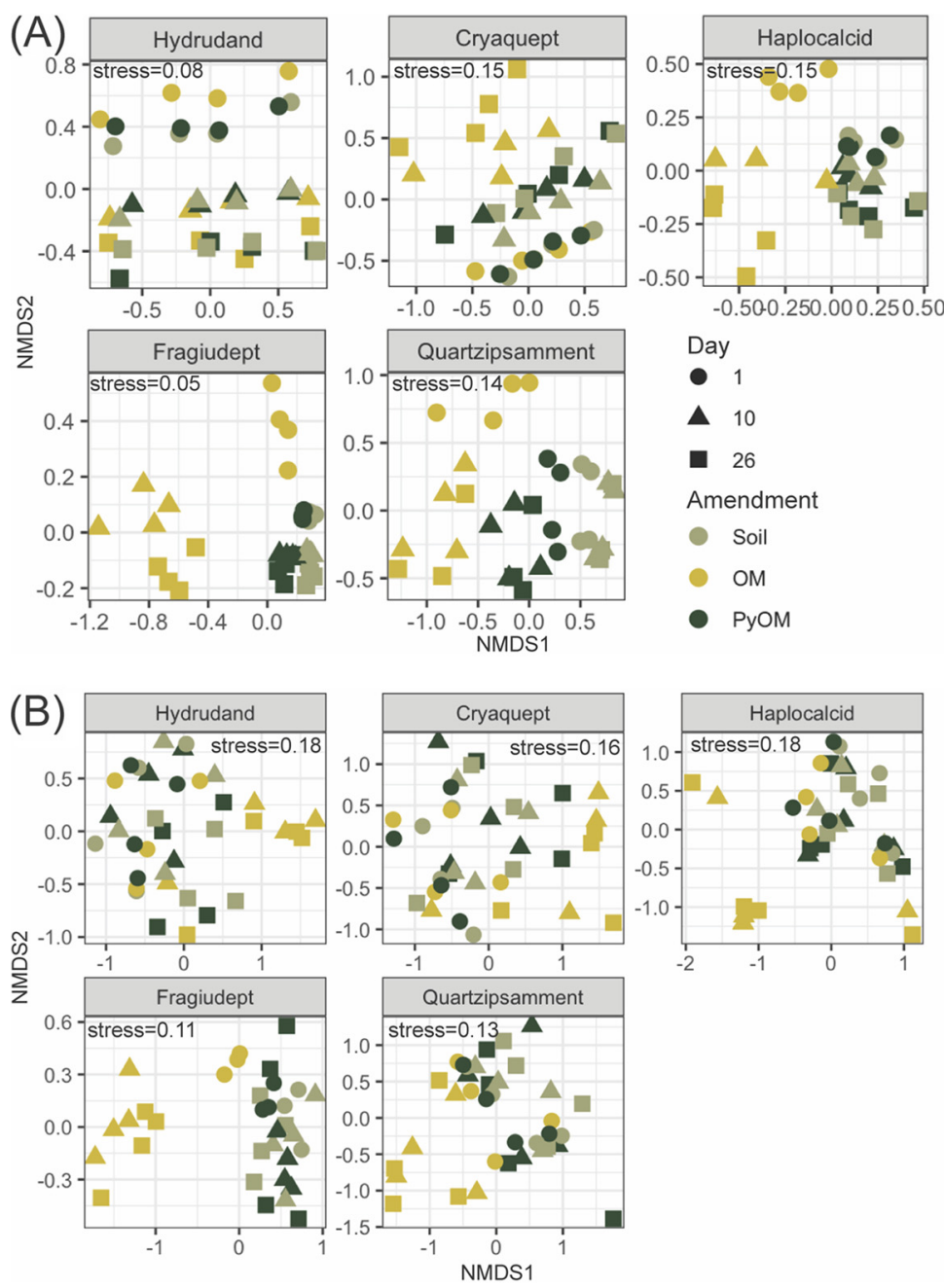

FIG 4 Nonmetric multidimensional scaling plots of Bray-Curtis dissimilarities between soil microbial communities (Hellinger-transformed relative abundances) at all three time points ( 1 day, 10 days, and 26 days) for each (previously frozen) soil. Shapes indicate whether organic matter (OM), pyrogenic organic matter (PyOM), or nothing (soil) was added. (A) Bacteria and Archaea (16S) ( $k=2$, stress $_{\text {Hydrudand }}=0.08$, stress $_{\text {Cryaquept }}=0.15$, stress $_{\text {Haplocalcid }}=0.15$, stress $_{\text {Fragiudept }}=0.05$, and stress $\left._{\text {Quartzipsamment }}=0.14\right)(n=4$ for each time point, except for Haplocalcid on day 10 and Quartzipsamment on day 26, where $n=3$ ). Ordinations were performed individually for each soil type. (B) Fungi (ITS2) $\left(k=2\right.$, stress $_{\text {Hydrudand }}=0.18$, stress $_{\text {Cryaquept }}=0.16$, stress $_{\text {Haplocalcid }}=0.18$, stress $_{\text {Fragiudept }}=$ 0.11 , and stress Ouartzipsamment $=0.13)(n=4$ for each time point, except for Fragiudept on day 1 , where $n=3$ ). Ordinations were performed individually for each soil type.

Fragiudept and Penicillium and Sporormiaceae in the Haplocalcid, were identified as being significant positive responders to PyOM, and no fungi were positive responders to OM over the time frame of this study (Table S11). Of the responsive 16S OTUs, 77 were responders to PyOM in at least one soil as well as to OM in at least one soil, or "common positive responders." Genera with common positive responders in multiple soils included Flavisolibacter (3 OM-responsive OTUs in 1 soil and 3 PyOM-responsive OTUs across 2 soils), Bacillus (29 OM-responsive OTUs across all 5 soils and 6 PyOM-responsive OTUs across 2 soils), Microvirga (18 OM-responsive OTUs across 3 soils and 8 PyOM-responsive OTUs across 3 soils), and Noviherbaspirillum (8 OM-responsive OTUs across 3 soils and 5 PyOM-responsive OTUs across 2 soils). With a few exceptions, bacterial taxa that responded positively or negatively to PyOM tended to also respond similarly to OM (Fig. 6). There was a significant positive relationship between the responses to the two amendments $(P<0.0001$ in a linear model). 

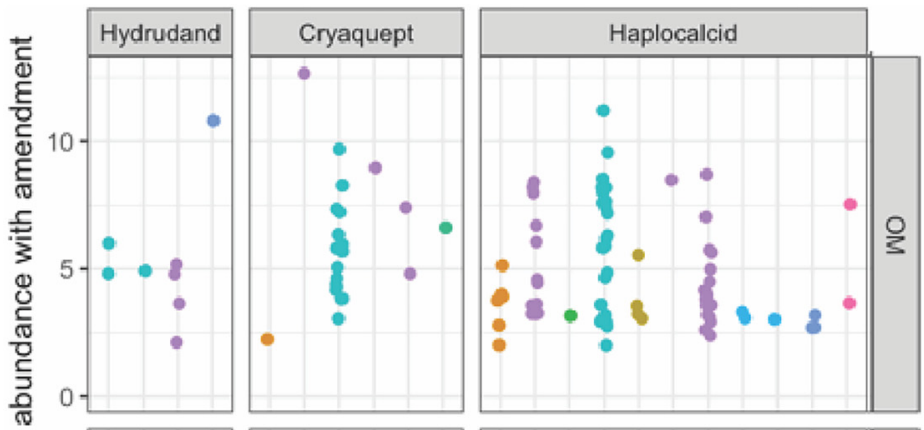

Phylum
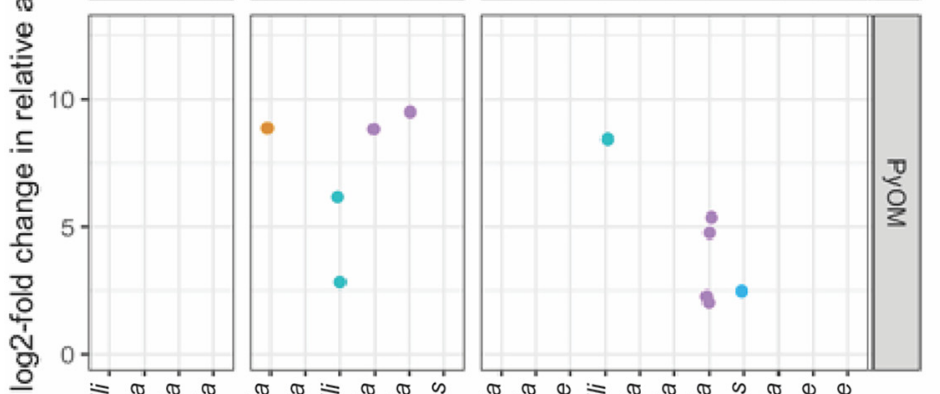

- Acidobacteria

- Actinobacteria

- Bacteroidetes

- Bacterial Rice Cluster 1

- (BRC1)

- Chloroflexi

- Eremiobacterota (WPS-2)

- Firmicutes

- Gemmatimonadetes

- Planctomycetes

- Proteobacteria

- Thaumarchaeota

- Verrucomicrobia
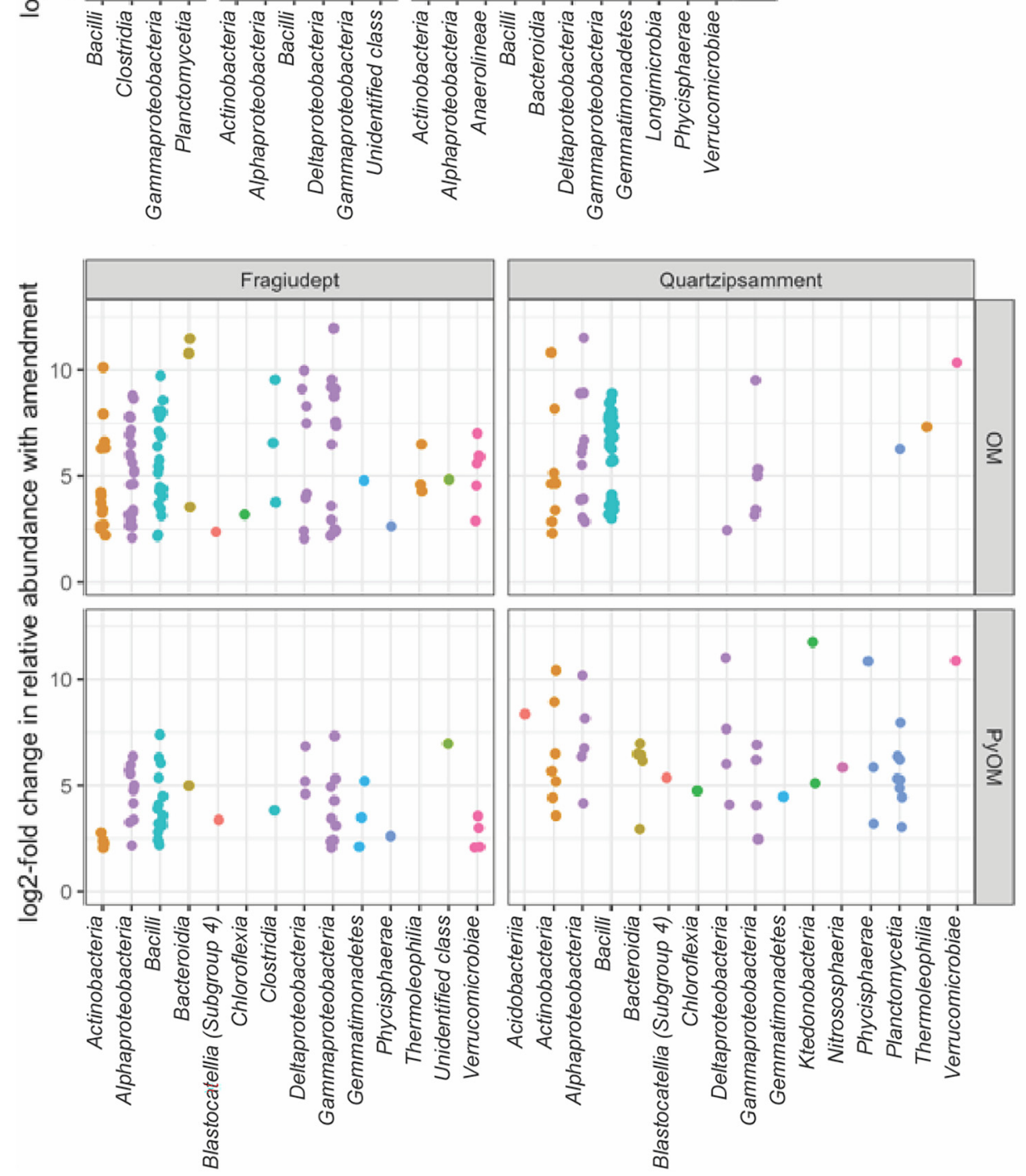

FIG 5 Differential abundances of bacterial and archaeal OTUs that are positive responders ( $\log _{2}$ fold change of $\geq 2$ ) to $\mathrm{OM}$ or PyOM additions in previously frozen soils, as estimated using the "corncob" algorithm (35) and grouped by soil and class. Each point represents a single OTU. 


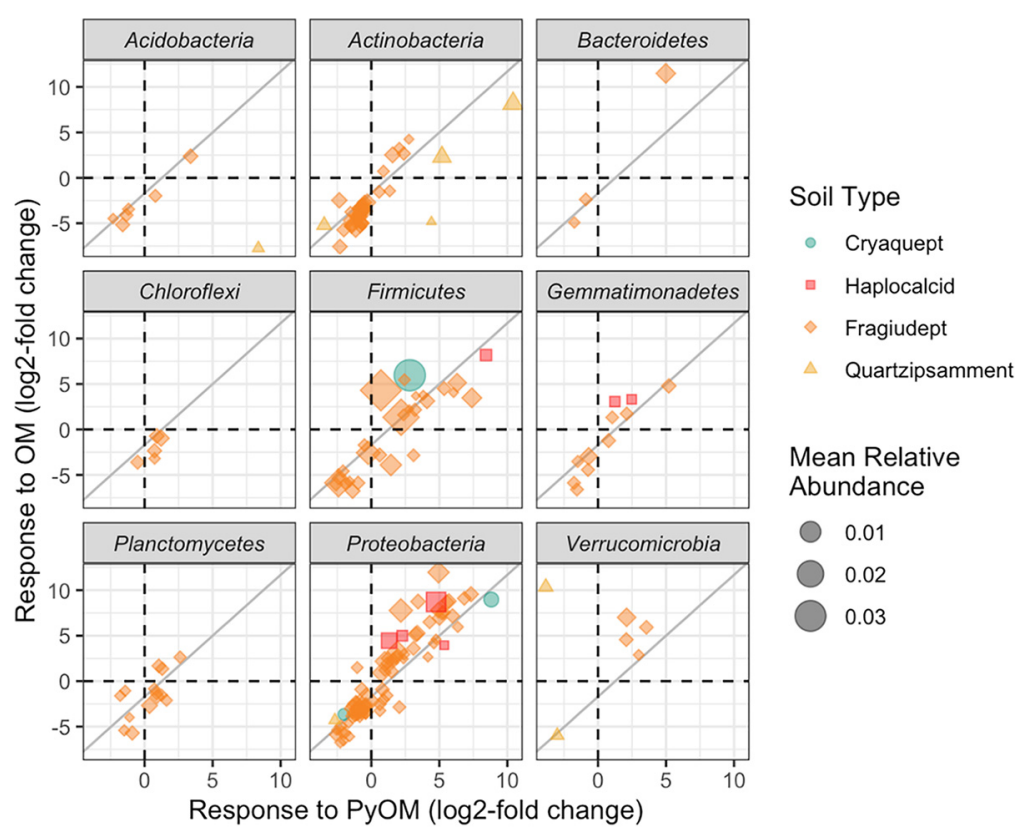

FIG 6 Response to PyOM versus response to OM for bacterial OTUs that were present at a mean of at least $0.01 \%$ and that were present in OM-amended, PyOM-amended, and unamended previously frozen soils, as estimated using the corncob algorithm (35). Each point represents a single OTU from one soil, with color and shape indicating soil source and size scaled by mean relative abundance within a soil, across all treatments, on days 10 and 26. Dashed black lines indicate zero, or no change in relative abundance compared to unamended soil. The solid gray lines indicate the linear fit for all phyla $\left[(\right.$ response to $\mathrm{OM})=-1.7+1.3 \times($ response to $\mathrm{PyOM}) ; P<0.001 ; R^{2}$ adj $\left.=0.63\right]$.

\section{DISCUSSION}

Effects of organic amendments on nSOC-derived $\mathrm{CO}_{2}$ reflect baseline soil $\mathrm{C}$ status. In response to our first question, our findings were consistent with our primary hypothesis: soils with lower baseline $\mathrm{CO}_{2}$ emissions experienced greater increases in $\mathrm{nSOC}$ mineralization with additions of OM or PyOM (Fig. 1 and 2). Simultaneously, increases in $\mathrm{nSOC}$ mineralization were greater with additions of OM than with additions of PyOM. These results are consistent with the idea that the activities of such microbial communities are more likely to be limited by $C$ availability such that the addition of PyOM could alleviate this constraint, resulting in generally increased microbial activity and, thus, increased SOC mineralization. In particular, the already low-C Quartzipsamment from Florida was especially vulnerable to increased nSOC losses with amendments. Although the Haplocalcid and Fragiudept soils also tended to have increased nSOC losses with the addition of PyOM, the Quartzipsamment was the only soil for which this effect was statistically significant for PyOM additions. These findings are consistent with previous studies across a range of soils and SOC contents (19-22). However, it is important to note that numerous other mechanisms could also contribute meaningfully to increased nSOC mineralization with organic amendments, as observed in other systems $(17,19,20)$ and as described in the introduction. However, we do not believe that the effects that we observed were primarily driven by $\mathrm{pH}$ shifts: the $\mathrm{pHs}$ of four of the five soils were very similar (5.0 to 5.2). Additionally, we do not believe that the increases in $\mathrm{nSOC}$ mineralization were driven primarily by the effects of the amendments on moisture: we adjusted moisture individually for each treatment. We do not believe that the effects were driven primarily by alleviation of a nutrient constraint with the addition of PyOM: the PyOM had relatively low $\mathrm{N}$, and furthermore, previous studies have often shown that soil $\mathrm{CO}_{2}$ emissions are inhibited by mineral $\mathrm{N}$ additions (36). Additionally, although the strongly responding Quartzipsamment had the lowest measured mineral nutrient concentrations ( $\mathrm{Ca}, \mathrm{Mg}$, and $\mathrm{K}$ ) (Table 1), the highest/second-highest-nutrient soil was the Fragiudept, and it had the next strongest 
$\mathrm{CO}_{2}$ response to PyOM and $\mathrm{OM}$ amendments, suggesting that alleviation of nutrient limitations with PyOM or OM additions was not the dominant mechanism driving our observed effects.

On the one hand, the fact that the amendments had the least effect on the high- $C$ soils suggests that, overall, the effects of increased nSOC mineralization with PyOM amendments might be less concerning since the highest- $C$ soils are less responsive. On the other hand, one might interpret it as being more concerning since soils with the lowest SOC and the lowest microbial activity to begin with are most at risk for increased nSOC losses with PyOM amendments. This raises the question of which soils would be the best candidates for $\mathrm{OM}$ or PyOM additions. High-C soils seem to have lower risks for short-term increased $\mathrm{CO}_{2}$ emissions. However, other benefits to low- $\mathrm{C}$ soils, such as changes to the water-holding capacity or total SOC content (PyOM-C plus SOC), might outweigh this trade-off.

Even though our results strongly support the finding that short-term increases in $\mathrm{CO}_{2}$ emissions are most likely to occur in soils with low $\mathrm{C}$ and/or low mineralization rates to begin with, it is important to note that these effects were observed over the short term, i.e., over just a few weeks. As in other studies, in the time period during which amendments increased net nSOC-derived $\mathrm{CO}_{2}$ emissions, the net increase usually began to level off or even began to decrease. Given this observation, and since other studies have observed net negative effects of PyOM amendments on nSOCderived $\mathrm{CO}_{2}$ emissions over longer time periods $(16,17)$, the findings from this study should be considered primarily within the context of short-term responses to amendments.

The magnitude of microbial community composition change mirrors the magnitude of increases in $\mathbf{n S O C}-\mathrm{CO}_{2}$. In response to our second question, our findings were also consistent with our primary hypothesis: we found that the degree to which soil microbial communities change with PyOM or OM amendments reflected the degree to which nSOC mineralization also increased (Fig. 4). From these results, we hypothesize that the taxa that respond positively to PyOM and especially OM additions may also be the same taxa that are responsible for increased nSOC mineralization with PyOM or OM additions. Thus, a stronger shift toward these groups is accompanied by a stronger effect on $\mathrm{nSOC}$ mineralization. That said, it is important to note that because we did not directly trace the fate of the organic substances into taxon-specific microbial biomass (e.g., using an approach such as stable isotope probing), we have not conclusively demonstrated that the microbes that increased in abundance with additions were also the ones that metabolized the larger amount of nSOC; rather, this would be a future hypothesis to test. Overall, OM additions resulted in both a larger change in community composition and a larger increase in $\mathrm{nSOC}$ mineralization than did PyOM additions.

PyOM responders differ across soils and do not reflect a common charosphere. Although PyOM additions had a significant effect on microbial community composition, PyOM-induced changes in community composition were much smaller than the differences in community composition between different soils (Fig. 3; see also Tables S4 and S5 and Fig. S1 and S2 in the supplemental material). Thus, PyOM did not result in a community dominated by the "charosphere" $(33,34)$ but, rather, resulted in detectable but relatively subtle shifts within a few of the existing taxa (Fig. 5 and 6). We made a similar observation in our recent review of the effects of PyOM additions on soil bacterial community composition (27). The current study substantially improves our confidence in that observation since it is not constrained by the challenges of cross-study differences in methods and materials and spans five different soils. Together, these observations underscore the importance of considering the effects of PyOM within the unique context of a given soil rather than generalizing the effects of PyOM on soil microbial communities across all soils.

We were also interested in the specific taxa that responded to PyOM additions. In a previous field trial with the same Fragiudept soil and similar amendments (25), we identified a number of "common responders" to PyOM and OM after 82 days in the 
field. We suggested that those taxa may most likely be responsible for the short-term $\mathrm{C}$ mineralization effects of PyOM additions, and we predicted that we would observe a similar phenomenon in the current study, possibly even across soils. This general trend persisted (Fig. 6 ) in that the OTU responses to the two amendments were significantly positively correlated $(P<0.0001)$; i.e., taxa that responded (positively or negatively) to one amendment tended to respond similarly to the other. Although there are a few taxa that are exceptions to this (they respond positively to one amendment but negatively to the other), we hesitate to dwell too much on this response since they tend to be low-abundance taxa to begin with. Because the same taxa that responded to PyOM over the short term also responded positively to $\mathrm{OM}$, we suggest that this supports the idea that PyOM-responsive taxa in this study were likely responding to the small fraction of easily mineralizable PyOM-C, supporting the idea that a responsive fraction of the overall community might be responsible for short-term increases in nSOC mineralization with PyOM amendments. Over longer timescales, we might expect different results as other mechanisms emerge. However, we were not necessarily able to identify a "core set" of PyOM responders across different soils. This is likely due in part to the small response overall to PyOM in the higher- $C$ soils and also to the diversity of organisms between soils. While there were 162 different PyOM-responsive OTUs, the same OTUs were often not present in the different soils: $62 \%$ of all $16 \mathrm{~S}$ OTUs were detected (regardless of abundance) in only a single unamended soil (97\% for ITS2), and $26 \%$ of all $16 \mathrm{~S}$ OTUs were detected in only two different soils (2\% for ITS2). In particular, since we used the dada2 OTU-picking algorithm, which can differentiate OTUs that differ by a single base pair, or "amplicon sequence variants," it may be useful to consider common responders at a coarser phylogenetic scale. If we consider the OTUs at the genus level, there were numerous bacterial genera with OTUs that were responsive to PyOM in multiple soils, as well as OM amendments, as described in Results. Some of the genera with PyOM-responsive OTUs across more than one soil were also identified as having PyOM-responsive OTUs in multiple studies in our previous meta-analysis, including Flavisolibacter, Microvirga, and Noviherbaspirillum (27). Additionally, some of these PyOM-responsive bacteria are from genera that have been identified as being fire responsive in other studies (e.g., Microvirga [37], Bacillus [38], and Noviherbaspirillum [39]), although we remind the reader that taxa even from the same genus can differ meaningfully in their functions (40). Because all of the named taxa were also responsive to OM amendments over the short term, we raise the question of whether these OTUs may be responding to the more easily mineralizable fractions of PyOM or, in the case of fires, also to fire-released OM. Together, these taxa could represent interesting candidates for future investigation of the ecology of fire- and PyOM-responsive bacteria.

Conclusions and outlook. While our short-term incubation indicates that low-C soils might be at the greatest risk for short-term $\mathrm{C}$ losses with OM or PyOM amendments, we note that the losses were greater with OM than with PyOM additions and that many studies have shown that these short-term effects are relatively limited and often even become net $\mathrm{C}$ increases over longer timescales. Together, our findings indicate that changes in microbial community composition mirrored changes in $\mathrm{nSOC}$ mineralization. This suggests that it may be likely that the change in $\mathrm{CO}_{2}$ emissions with the addition of amendments is governed by a specific subset of the microbial community, rather than a general stimulation of the entire community. Although these specific responsive organisms were not consistent across all soils and depend on the native microbial community, certain taxa were identified as common responders. Future research could utilize techniques such as stable isotope probing to conclusively demonstrate which microbes are using the amendments as a $C$ source and to expand the research to more soil types, different timescales, and different PyOM materials to begin to develop a more comprehensive understanding of the specific microbial responders. It would also be interesting to determine whether or when our observation does not hold: whether there are 
conditions under which large community changes in response to organic amendments are not accompanied by changes in $\mathrm{nSOC}-\mathrm{CO}_{2}$ emissions and, conversely, whether there are conditions where large changes in $\mathrm{CO}_{2}$ emissions are observed but not accompanied by changes in microbial community composition.

\section{MATERIALS AND METHODS}

Soil descriptions. Soil properties are described in Table 1. Four of the soils were collected from National Ecological Observatory Network (NEON) sites according to NEON protocols in 2009 to 2010, as part of a NEON prototype study, from the top 0 to $0.1 \mathrm{~m}$ of the A horizon (41). We added a local nonNEON site in which we had previously investigated PyOM effects on SOC cycling and microbial communities (the Fragiudept/New York site). Each sample replicate was from a single core, except for the Cryaquept and Fragiudept, which were from composited cores. Samples were stored at $-80^{\circ} \mathrm{C}$ until experimental initiation, except for being shipped overnight to Ithaca, NY, on dry ice. Clearly, this treatment would be expected to have an effect on the specific soil community composition after thawing and incubation (42). Due to logistical constraints in collecting fresh soils from all sites, and in order to treat all soils equivalently, we worked with frozen samples. Thus, we would expect our findings for these soils with respect to factors such as the identification of specific taxa as having the ability to respond to PyOM amendments or the positive relationship between total microbial community composition shifts and increased nSOC mineralization with amendments to remain applicable in other systems, while the specific numeric values (e.g., baseline abundances of individual taxa or absolute magnitude of $\mathrm{CO}_{2}$ fluxes) and taxa that were not identified as positive responders should not be directly translated to natural ecosystems.

Corn stover and PyOM amendment production. ${ }^{13} \mathrm{C}$ pulse-labeled corn [Zea mays (L.)] shoot biomass was grown, ground $(<2 \mathrm{~mm})$, and pyrolyzed at $350^{\circ} \mathrm{C}$ under Ar gas in a modified muffle furnace as previously described in detail (43). Amendment properties are reported in Table S1 in the supplemental material.

Incubation setup and monitoring. Frozen samples were thawed, sieved through a $<2-\mathrm{mm}$ sieve, and air dried at room temperature until the mass stabilized with losses changing by less than $1 \%$ per day. A subsample was rapidly dried at $70^{\circ} \mathrm{C}$ in a drying oven and used to determine the moisture-holding capacity individually for each soil, with each amendment, in order to ensure that all samples are at equivalent moisture levels given that amendments might affect the water-holding capacity. To do this, we weighed the soil samples (amended or unamended) in a PVC tube with a screen covered by a moist filter paper at the bottom. The tubes were placed into a container, and water was slowly added to the container until the samples were saturated and the level of the water was level to the surface of the soil. The saturated soils were allowed to stand overnight. In the morning, they were removed from the water bath and allowed to drain freely overnight, covered in parafilm. The mass of water remaining in the soil was taken to represent the "field capacity" (FC), with a target moisture value for incubation of $65 \%$ FC. We also calculated the final moisture content of the air-dried soil to enable us to calculate the water required to reach this value for the incubations.

We prepared separate incubation vials for each treatment to be sampled at each time point. For vials with amendments, we added OM at 3\% by mass, and added PyOM on a prepyrolysis mass basis, which resulted in a $0.99 \%$ by mass addition; i.e., we added the mass of PyOM that would have remained if we used the same amount of initial biomass to produce PyOM, essentially asking the systems-level question, what might the fate of this biomass be? Based on our expectations for $\mathrm{CO}_{2}$ flux rates from previous experiments, we determined that we would require $1 \mathrm{~g}$ soil per incubation for the high-organic-matter soils (typic Hydrudand and perigelic Cryaquept) and $5 \mathrm{~g}$ per incubation for the lower-organic-matter soils in order to make sure that $\mathrm{CO}_{2}$ fluxes remained within the optimal range for our instrumentation setup. For the 24-h time points, we used $2 \mathrm{~g}$ of soil to conserve soil. Each jar, amended and unamended, was stirred to mix. The experiment was initiated (time zero $\left[t_{0}\right]$ ) for each jar when water was added to bring it up to $65 \%$ FC. At wet-up, each jar received water dropwise to gradually bring it up to the target moisture level. The vial for the 24-h time point was incubated at $30^{\circ} \mathrm{C}$ for $24 \mathrm{~h}$ in Mason jars with $20 \mathrm{ml}$ deionized water (DIW) in the bottom to maintain a moist environment and was then destructively sampled for microbial community composition after exactly $24 \mathrm{~h}$ by collecting the entire sample in a Whirl-Pak bag. The sample was immediately frozen at $-80^{\circ} \mathrm{C}$ and stored until DNA extraction, except for overnight shipment on dry ice to Madison, WI. The two vials for the two later time points, 10 days and 26 days, were placed into the same quartsize Mason jar along with $20 \mathrm{ml}$ DIW in the bottom of the Mason jar to maintain a moist environment. The Mason jar was then sealed with a lid with tubing connected to the gas monitoring system. Because each full measurement cycle on the gas monitoring system takes 20 min, one experimental treatment was wet up every 20 min, taking care to attach it to the gas monitoring system at the corresponding time. The jars were automatically sampled using a custom-built multiplexer system (see reference 17 for details) connected to a cavity ring-down spectrometer (G2201-I; Picarro, Santa Clara, CA, USA) that measures $\mathrm{CO}_{2}$ concentrations and ${ }^{13} \mathrm{CO}_{2} /{ }^{12} \mathrm{CO}_{2}$ isotopes. Measurements were made on a continuous monitoring cycle, which resulted in each Mason jar being measured about once a day. After 10 days, jars were opened, and one vial was randomly removed to be destructively sampled for microbial community characterization. Mason jars were removed and returned on a time cycle to ensure that each vial was sampled at the equivalent time since wet-up. After 26 days, the second vial was removed and destructively sampled for microbial community characterization. 
TABLE 2 PCR and sequencing primers used in this study ${ }^{a}$

\begin{tabular}{ll}
\hline Primer & Sequence $^{b}$ \\
\hline $16 \mathrm{~S}$ Illumina & \\
$515 \mathrm{f}$ & AATGATACGGCGACCACCGAGATCTACACXXXXXXXXTATGGTAATTGTGTGYCAGCMGCCGCGGTAA \\
$806 \mathrm{r}$ & CAAGCAGAAGACGGCATACGAGATXXXXXXXXAGTCAGCCAGCCGGACTACNVGGGTWTCTAAT \\
Read $1 \mathrm{seq}$ & TATGGTAATTGGTGYAGCMGCCGCGGTAA \\
Read $2 \mathrm{seq}$ & AGTCAGCCAGCCGGACTACNVGGGTWTCTAAT \\
Barcode seq & ATTAGAWACCCBNGTAGTCCGGCTGGCTGACT \\
& \\
ITS2 Illumina & \\
ITS4 & AATGATACGGCGACCACCGAGATCTACACXXXXXXXXTATGGTAATTAAAGCCTCCGCTTATTGATATGCTTAART \\
5.85 & CAAGCAGAAGACGGCATACGAGATXXXXXXXXAGTCAGTCAGGGACTTYRRCAAYGGATCWCT \\
Read $1 \mathrm{seq}$ & TATGGTAATTAAAGCCTCCGCTTATTGATATGCTTAART \\
Read $2 \mathrm{seq}$ & AGTCAGTCAGGGAACTTYRRCAAYGGATCWCT \\
Barcode seq & AGWGATCCRTTGYRAAAGTCCCTGACTGACT \\
\hline
\end{tabular}

a See references 44-46. Full Illumina PCR primers with barcodes are listed in Tables S2 and S3 in the supplemental material.

${ }^{b}$ The barcode is shown in italic type, and the pad and linker are shown in boldface type.

DNA extraction and sequencing. DNA extractions were performed for each sample and for the original materials (OM and PyOM), with one blank extraction for every 24 samples (identical methods but using empty tubes, all of which were sequenced). We used a DNeasy PowerLyzer PowerSoil DNA extraction kit (Qiagen, Germantown, MD) according to the manufacturer's instructions and bead-beating samples for $45 \mathrm{~s}$ at $6 \mathrm{~m} \mathrm{~s}^{-1}$ on a FastPrep $5 \mathrm{G}$ homogenizer (MP Biomedicals, Santa Ana, CA). Extracted DNA was amplified in triplicate PCRs, targeting the 16S rRNA gene v4 region (here "16S") with primers $515 f$ (GTGYCAGCMGCCGCGGTAA) and 806r (GGACTACNVGGGTWTCTAAT) (44) and targeting the ITS2 gene region with primers 5.8S-Fun (AACTITYRRCAAYGGATCWCT) and ITS4-Fun (AGCCTCCGCTTATTGA TATGCTTAART) (45), with barcodes and Illumina sequencing adapters added as described previously (46) (Table 2; see Tables S3 and S4 in the supplemental material for full primers with all barcodes and adapters). The PCR amplicon triplicates were pooled, purified, and normalized using a SequalPrep normalization plate (96) kit (Thermo Fisher Scientific, Waltham, MA). Samples, including blanks, were pooled, and library cleanup was performed using a Wizard SV gel and PCR cleanup system (catalog number A9282; Promega, Madison, WI). The pooled library was submitted to the University of WisconsinMadison Biotechnology Center (Madison, WI) for 2-by-250 paired-end (PE) Illumina MiSeq sequencing for the $16 \mathrm{~S}$ amplicons and 2-by-300 PE sequencing for the ITS2 amplicons.

Microbial community bioinformatics. For $16 \mathrm{~S}$ reads (32,000 minimum, 208,000 maximum, and 58,000 median total sequenced reads), we quality filtered and trimmed, dereplicated and learned errors, assigned operational taxonomic units (OTUs), and removed chimeras using dada2 (47) as implemented in $\mathrm{R}$ (mean of $53 \%$ of the initial reads remaining after the full pipeline; 15,000 minimum, 180,000 maximum, and 29,000 median total final reads). Taxonomy was assigned to the $16 \mathrm{~S}$ reads using a naive Bayes classifier (48) trained on the $515 \mathrm{f}-806 \mathrm{r}$ region of the $99 \%$ identity OTUs from the Silva $\mathrm{nr}$ 132 database $(49,60)$ as implemented in QIIME2 (50). We removed any OTUs classified as chloroplasts or mitochondria. For ITS2 reads (21,000 minimum, 289,000 maximum, and 62,000 median total sequenced reads), we first merged reads using PEAR (51) and then performed the same steps as described above for $16 \mathrm{~S}$ (mean of $50 \%$ of the initial reads remaining after the full pipeline; 6,000 minimum, 199,000 maximum, and 32,000 median total final reads). Taxonomy was assigned to the ITS2 reads using the UNITE general release dynamic threshold database (2 February 2019) using a naive Bayes classifier (48) as implemented in dada2 (47). We removed any OTUs that did not receive a classification at the phylum level in order to exclude any nonfungal ITS2 sequences. High-memory-intensive sequence processing steps were performed at the UW-Madison Center for High Throughput Computing cluster (Madison, WI).

Stable isotope $\mathrm{CO}_{2}$ flux partitioning. Respiration data were analyzed as described previously (17) using $\mathrm{R}$ version 3.6.1 (52). Sample respiration was partitioned between the amendment-derived $\mathrm{CO}_{2}-\mathrm{C}$ and soil-derived $\mathrm{CO}_{2}-\mathrm{C}$ using the equations $\delta_{\text {measured }}=\delta_{\text {soil }} \times f_{\text {soil }}+\delta_{\text {amendment }} \times f_{\text {amendment }}$ and $\mathrm{CO}_{2}-$ $\mathrm{C}_{\text {total }}=\mathrm{CO}_{2}-\mathrm{C}_{\text {soil }}+\mathrm{CO}_{2}-\mathrm{C}_{\text {amendment }}$, where $\delta$ represents the $\delta^{13} \mathrm{C}$ signature (with respect to the PeeDee belemnite standard) of the total respired $\mathrm{CO}_{2}-\mathrm{C}\left(\delta_{\text {measured }}\right)$, the soil-derived $\mathrm{CO}_{2}\left(\delta_{\text {soil }}\right)$, or the amendment-derived $\mathrm{CO}_{2}-\mathrm{C}\left(\delta_{\text {amendment }}\right)$ and $f$ represents the fraction of the total $\mathrm{CO}_{2}-\mathrm{C}$ derived from the soil $\left(f_{\text {soil }}\right)$ or the amendment $\left(f_{\text {amendment }}\right)(53) . \delta^{13} \mathrm{C}$ of bulk PyOM ( $\left.\delta_{\text {PyOM }}\right)$ or bulk OM $\left(\delta_{\text {OM }}\right)$ was used as the amendment end-member for isotope partitioning. Soil isotope end-members $\left(\delta_{\text {soil }}\right)$ to be used in isotope partitioning were obtained daily using the average $\delta^{13} \mathrm{C}$ for $\mathrm{CO}_{2}-\mathrm{C}$ from control (unamended) treatments (see the R scripts at https://github.com/TheaWhitman/NEON_PyOM). We interpret values that do not overlap in a $95 \%$ confidence interval as being significantly different.

Microbial community analyses. We worked primarily in Jupyter notebooks, with phyloseq (54), ggplot (55), and dplyr (56) being instrumental in working with the data in R (52). We compared community compositions across samples using Bray-Curtis dissimilarities (57) on Hellinger-transformed relative abundances (58), which we represented using nonmetric multidimensional scaling (NMDS) ordinations. We tested for significant effects of soil site, days of incubation, amendment, and interactions between 
soil and day and between soil and amendment using permutational multivariate analysis of variance (PERMANOVA) (the adonis function in vegan [59]). We also tested whether baseline soil properties- $\mathrm{pH}$, $\mathrm{CEC}, \mathrm{Ca}, \mathrm{Mg}, \mathrm{Na}$, $\mathrm{K}$, total $\mathrm{C}$, and total $\mathrm{N}$-were correlated with the initial community composition in the unamended soils using PERMANOVA. We identified OTUs that were differentially abundant (significantly enriched in amended soils compared to control soils) within each soil type and amendment, testing only taxa that represented at least $0.01 \%$ of the mean total community for that soil using the $\mathrm{R}$ package corncob (35). We analyzed the two later time points together, while controlling for time point and controlling for differential variance, using a Wald test and correcting $P$ values to yield a false discovery rate of less than 0.05 within each soil type and amendment. We fit a linear model for the response to $\mathrm{OM}$ versus the response to PyOM for taxa with significant responses to at least one of the amendments.

Data availability. Sequencing data are available in the NCBI SRA under BioProject accession number PRJNA687484 and BioSample accession numbers SAMN17145005 to SAMN17145200. Code used to analyze data and generate figures in this paper is available at https://github.com/TheaWhitman/NEON _PyOM.

\section{SUPPLEMENTAL MATERIAL}

Supplemental material is available online only.

SUPPLEMENTAL FILE 1, PDF file, 0.2 MB.

SUPPLEMENTAL FILE 2, CSV file, $0.01 \mathrm{MB}$.

SUPPLEMENTAL FILE 3, CSV file, $0.01 \mathrm{MB}$.

SUPPLEMENTAL FILE 4, CSV file, 0.2 MB.

SUPPLEMENTAL FILE 5, CSV file, 0.01 MB.

\section{ACKNOWLEDGMENTS}

We thank Dominic Woolf, who was instrumental in helping develop the original $\mathrm{R}$ script that was modified to analyze these data. We thank the NEON project, including Dave Tazik, Lee Stanish, and Samantha Weintraub for helping us access the NEON soils. We also acknowledge the following individuals and organizations for providing soils for an initial planned version of the experiment, which were, unfortunately, ultimately lost when a freezer broke down: John Anderson, Bernice Gamboa, and the Jornada Experimental Range; William J. McShea and the Smithsonian Conservation Biology Institute; Mitch McClaran and the Santa Rita Experimental Range; Petra Royston, Ben Gottloeb, Robert Nelson, and the Disney Wilderness Preserve; Audrey Barker-Plotkin and the Harvard Forest; Stephen Coates and the Ordway-Swisher Biological Station; Isabel Ashton, Tracey Baldwin, Craig Emerson, the Rocky Mountain National Park, Central Plains Experimental Range, and the North Sterling NEON sites; Holly Johnson, Matt Sanderson, Mark Liebig, and the Northern Great Plains Research Lab; Ty Lindberg at NEON; and all others who helped collect and ship those soils.

The National Ecological Observatory Network is a program sponsored by the National Science Foundation and operated under a cooperative agreement by Battelle Memorial Institute. This material is based in part upon work supported by the National Science Foundation through the NEON Program. An NSF doctoral dissertation improvement grant award to T.W. and J.L. supported the bulk of this research (NSF1406195); the U.S. Department of Energy also helped support T.W. (DE-SC0016365). This research was performed using the computing resources and assistance of the UWMadison Center for High Throughput Computing (CHTC) in the Department of Computer Sciences. The CHTC is supported by UW-Madison, the Advanced Computing Initiative, the Wisconsin Alumni Research Foundation, the Wisconsin Institutes for Discovery, and the National Science Foundation and is an active member of the Open Science Grid, which is supported by the National Science Foundation and the U.S. Department of Energy's Office of Science.

T.W. and J.L. were responsible for the experimental design. T.W., S.D., K.H., A.E., and J.L. developed and optimized the experimental conditions. S.D., K.H., and A.E. set up and ran the in-lab experiment. T.W. and J.W. performed the DNA extractions, sequencing, and microbial bioinformatics. T.W. analyzed the data, and T.W. and J.L. interpreted the data. T.W. drafted the manuscript, and all authors contributed to, read, and approved the manuscript. 


\section{REFERENCES}

1. Ciais P, Sabine C, Bala G, Bopp L, Brovkin V, Canadell J, Chhabra A, DeFries R, Galloway J, Heimann M, Jones C, Le Quéré C, Myneni RB, Piao S, Thornton P. 2013. Carbon and other biogeochemical cycles, p 465-570. In Stocker TF, Quin D, Plattner GK, Tignor M, Allen SK, Boschung J, Nauels A, Xia Y, Bex V, Midgley PMP (ed), Climate change-the physical science basis. Contribution of Working Group I to the Fifth Assessment Report of the Intergovernmental Panel on Climate Change. Cambridge University Press, Cambridge, United Kingdom.

2. Schmidt MWI, Torn MS, Abiven S, Dittmar T, Guggenberger G, Janssens IA, Kleber M, Kögel-Knabner I, Lehmann J, Manning DAC, Nannipieri P, Rasse DP, Weiner S, Trumbore SE. 2011. Persistence of soil organic matter as an ecosystem property. Nature 478:49-56. https://doi.org/10.1038/ nature10386.

3. Zimmerman AR, Mitra S. 2017. Trial by fire: on the terminology and methods used in pyrogenic organic carbon research. Front Earth Sci 5:354.

4. Jones MW, Santín C, Van Der Werf GR, Doerr SH. 2019. Global fire emissions buffered by the production of pyrogenic carbon. Nat Geosci 12:742-747. https://doi.org/10.1038/s41561-019-0403-x.

5. Reisser M, Purves RS, Schmidt MWI, Abiven S. 2016. Pyrogenic carbon in soils: a literature-based inventory and a global estimation of its content in soil organic carbon and stocks. Front Earth Sci 4:80.

6. Lehmann J. 2007. A handful of carbon. Nature 447:143-144. https://doi .org/10.1038/447143a.

7. Laird DA. 2008. The charcoal vision: a win-win-win scenario for simultaneously producing bioenergy, permanently sequestering carbon, while improving soil and water quality. Agron J 100:178-181.

8. Wardle DA, Nilsson M-C, Zackrisson O. 2008. Fire-derived charcoal causes loss of forest humus. Science 320:629. https://doi.org/10.1126/science.1154960.

9. Wardle DA, Nilsson M-C, Zackrisson O. 2008. Response to comment on "Fire-derived charcoal causes loss of forest humus." Science 321:1295. https://doi.org/10.1126/science.1160750.

10. Lehmann J, Sohi S. 2008. Comment on "Fire-derived charcoal causes loss of forest humus." Science 321:1295. https://doi.org/10.1126/science.1160005.

11. Zimmerman AR, Gao B, Ahn M-Y. 2011. Positive and negative carbon mineralization priming effects among a variety of biochar-amended soils. Soil Biol Biochem 43:1169-1179. https://doi.org/10.1016/j.soilbio.2011.02.005.

12. Kuzyakov Y, Subbotina I, Chen H, Bogomolova I, Xu X. 2009. Black carbon decomposition and incorporation into soil microbial biomass estimated by ${ }^{14} \mathrm{C}$ labeling. Soil Biol Biochem 41:210-219. https://doi.org/10.1016/j soilbio.2008.10.016.

13. Luo Y, Durenkamp M, De Nobili M, Lin Q, Brookes PC. 2011. Short term soil priming effects and the mineralisation of biochar following its incorporation to soils of different pH. Soil Biol Biochem 43:2304-2314. https:// doi.org/10.1016/j.soilbio.2011.07.020.

14. Bingeman CW, Varner JE, Martin WP. 1953. The effect of the addition of organic materials on the decomposition of an organic soil. Soil Sci Soc Am J 17:34-38. https://doi.org/10.2136/sssaj1953.03615995001700010008x.

15. Blagodatskaya E, Kuzyakov Y. 2008. Mechanisms of real and apparent priming effects and their dependence on soil microbial biomass and community structure: critical review. Biol Fertil Soils 45:115-131. https://doi .org/10.1007/s00374-008-0334-y.

16. Whitman T, Zhu Z, Lehmann J. 2014. Carbon mineralizability determines interactive effects on mineralization of pyrogenic organic matter and soil organic carbon. Environ Sci Technol 48:13727-13734. https://doi.org/10 $.1021 /$ es503331y.

17. DeCiucies S, Whitman T, Woolf D, Enders A, Lehmann J. 2018. Priming mechanisms with additions of pyrogenic organic matter to soil. Geochim Cosmochim Acta 238:329-342. https://doi.org/10.1016/j.gca.2018.07.004.

18. Cheng H, Hill PW, Bastami MS, Jones DL. 2017. Biochar stimulates the decomposition of simple organic matter and suppresses the decomposition of complex organic matter in a sandy loam soil. Glob Change Biol Bioenergy 9:1110-1121. https://doi.org/10.1111/gcbb.12402.

19. Maestrini B, Nannipieri P, Abiven S. 2015. A meta-analysis on pyrogenic organic matter induced priming effect. Glob Change Biol Bioenergy 7:577-590. https://doi.org/10.1111/gcbb.12194.

20. Whitman T, Singh BP, Zimmerman AR. 2015. Priming effects in biocharamended soils: implications of biochar-soil organic matter interactions for carbon storage, p 455-487. In Lehmann J, Joseph S (ed), Biochar for environmental management, 2nd ed. Routledge, New York, NY.

21. Wang J, Xiong Z, Kuzyakov Y. 2016. Biochar stability in soil: meta-analysis of decomposition and priming effects. Glob Change Biol Bioenergy 8:512-523. https://doi.org/10.1111/gcbb.12266.
22. Ding F, van Zwieten L, Zhang W, Weng ZH, Shi S, Wang J, Meng J. 2018. A meta-analysis and critical evaluation of influencing factors on soil carbon priming following biochar amendment. J Soils Sediments 18:1507-1517. https://doi.org/10.1007/s11368-017-1899-6.

23. Woolf D, Lehmann J. 2012. Modelling the long-term response to positive and negative priming of soil organic carbon by black carbon. Biogeochemistry 111:83-95. https://doi.org/10.1007/s10533-012-9764-6.

24. Woolf D, Amonette JE, Street-Perrott FA, Lehmann J, Joseph S. 2010. Sustainable biochar to mitigate global climate change. Nat Commun 1:56. https://doi.org/10.1038/ncomms1053.

25. Whitman T, Pepe-Ranney C, Enders A, Koechli C, Campbell A, Buckley DH, Lehmann J. 2016. Dynamics of microbial community composition and soil organic carbon mineralization in soil following addition of pyrogenic and fresh organic matter. ISME J 10:2918-2930. https://doi.org/10.1038/ ismej.2016.68.

26. Yu Z, Chen L, Pan S, Li Y, Kuzyakov Y, Xu J, Brookes PC, Luo Y. 2018. Feedstock determines biochar-induced soil priming effects by stimulating the activity of specific microorganisms. Eur J Soil Sci 69:521-534. https://doi .org/10.1111/ejss.12542.

27. Woolet J, Whitman T. 2020. Review: pyrogenic organic matter effects on soil bacterial community composition. Soil Biol Biochem 141:107678. https://doi.org/10.1016/j.soilbio.2019.107678.

28. Dai Z, Hu J, Xu X, Zhang L, Brookes PC, He Y, Xu J. 2016. Sensitive responders among bacterial and fungal microbiome to pyrogenic organic matter (biochar) addition differed greatly between rhizosphere and bulk soils. Sci Rep 6:36101. https://doi.org/10.1038/srep36101.

29. Nielsen S, Minchin T, Kimber S, van Zwieten L, Gilbert J, Munroe P, Joseph $\mathrm{S}$, Thomas T. 2014. Comparative analysis of the microbial communities in agricultural soil amended with enhanced biochars or traditional fertilisers. Agric Ecosyst Environ 191:73-82. https://doi.org/10.1016/j.agee .2014.04.006.

30. Wu H, Zeng G, Liang J, Chen J, Xu J, Dai J, Li X, Chen M, Xu P, Zhou Y, Li F, $\mathrm{Hu}$ L, Wan J. 2016. Responses of bacterial community and functional marker genes of nitrogen cycling to biochar, compost and combined amendments in soil. Appl Microbiol Biotechnol 100:8583-8591. https:// doi.org/10.1007/s00253-016-7614-5.

31. Imparato V, Hansen V, Santos SS, Nielsen TK, Giagnoni L, HauggaardNielsen H, Johansen A, Renella G, Winding A. 2016. Gasification biochar has limited effects on functional and structural diversity of soil microbial communities in a temperate agroecosystem. Soil Biol Biochem 99:128-136. https://doi.org/10.1016/j.soilbio.2016.05.004.

32. Yao Q, Liu J, Yu Z, Li Y, Jin J, Liu X, Wang G. 2017. Changes of bacterial community compositions after three years of biochar application in a black soil of northeast China. Appl Soil Ecol 113:11-21. https://doi.org/10 .1016/j.apsoil.2017.01.007.

33. Quilliam RS, Glanville HC, Wade SC, Jones DL. 2013. Life in the "charosphere" - does biochar in agricultural soil provide a significant habitat for microorganisms? Soil Biol Biochem 65:287-293. https://doi.org/10.1016/j soilbio.2013.06.004.

34. Clough TJ, Condron LM. 2010. Biochar and the nitrogen cycle: introduction. J Environ Qual 39:1218-1223. https://doi.org/10.2134/jeq2010.0204.

35. Martin BD, Witten D, Willis AD. 2020. Modeling microbial abundances and dysbiosis with beta-binomial regression. Ann Appl Stat 14:94-115. https://doi.org/10.1214/19-aoas1283.

36. Ramirez KS, Craine JM, Fierer N. 2012. Consistent effects of nitrogen amendments on soil microbial communities and processes across biomes. Glob Change Biol 18:1918-1927. https://doi.org/10.1111/j.1365 -2486.2012.02639.x.

37. Fernández-González AJ, Martínez-Hidalgo P, Cobo-Díaz JF, Villadas PJ, Martínez-Molina E, Toro N, Tringe SG, Fernández-López M. 2017. The rhizosphere microbiome of burned holm-oak: potential role of the genus Arthrobacter in the recovery of burned soils. Sci Rep 7:6008. https://doi .org/10.1038/s41598-017-06112-3.

38. Cobo-Díaz JF, Fernández-González AJ, Villadas PJ, Robles $A B$, Toro N, Fernández-López M. 2015. Metagenomic assessment of the potential microbial nitrogen pathways in the rhizosphere of a Mediterranean forest after a wildfire. Microb Ecol 69:895-904. https://doi.org/10.1007/s00248 -015-0586-7.

39. Whitman T, Whitman E, Woolet J, Flannigan MD, Thompson DK, Parisien M-A. 2019. Soil bacterial and fungal response to wildfires in the Canadian boreal forest across a burn severity gradient. Soil Biol Biochem 138:13. 
40. Eren AM, Maignien L, Sul WJ, Murphy LG, Grim SL, Morrison HG, Sogin ML. 2013. Oligotyping: differentiating between closely related microbial taxa using 16S rRNA gene data. Methods Ecol Evol 4:1111-1119. https://doi .org/10.1111/2041-210X.12114.

41. National Ecological Observatory Network. 2016. Soil microbe prototype 16S sequence data, 2009-2010. National Ecological Observatory Network, Boulder, $\mathrm{CO}$.

42. Martí E, Càliz J, Montserrat G, Garau MA, Cruañas R, Vila X, Sierra J. 2012. Air-drying, cooling and freezing for soil sample storage affects the activity and the microbial communities from two Mediterranean soils. Geomicrobiol J 29:151-160. https://doi.org/10.1080/01490451.2010.530341.

43. Whitman T, Lehmann J. 2015. A dual-isotope approach to allow conclusive partitioning between three sources. Nat Commun 6:8708. https://doi .org/10.1038/ncomms9708.

44. Walters W, Hyde ER, Berg-Lyons D, Ackermann G, Humphrey G, Parada A, Gilbert JA, Jansson JK, Caporaso JG, Fuhrman JA, Apprill A, Knight R. 2016. Improved bacterial 16S rRNA gene (V4 and V4-5) and fungal internal transcribed spacer marker gene primers for microbial community surveys. mSystems 1:e00009-15. https://doi.org/10.1128/mSystems.00009-15.

45. Taylor DL, Walters WA, Lennon NJ, Bochicchio J, Krohn A, Caporaso JG, Pennanen T. 2016. Accurate estimation of fungal diversity and abundance through improved lineage-specific primers optimized for Illumina amplicon sequencing. Appl Environ Microbiol 82:7217-7226. https://doi.org/10 1128/AEM.02576-16.

46. Kozich JJ, Westcott SL, Baxter NT, Highlander SK, Schloss PD. 2013. Development of a dual-index sequencing strategy and curation pipeline for analyzing amplicon sequence data on the MiSeq Illumina sequencing platform. Appl Environ Microbiol 79:5112-5120. https://doi.org/10.1128/ AEM.01043-13.

47. Callahan BJ, McMurdie PJ, Rosen MJ, Han AW, Johnson AJA, Holmes SP. 2016. DADA2: high-resolution sample inference from Illumina amplicon data. Nat Methods 13:581-583. https://doi.org/10.1038/nmeth.3869.

48. Wang Q, Garrity GM, Tiedje JM, Cole JR. 2007. Naive Bayesian classifier for rapid assignment of rRNA sequences into the new bacterial taxonomy. Appl Environ Microbiol 73:5261-5267. https://doi.org/10.1128/AEM.00062-07.

49. Quast C, Pruesse E, Yilmaz P, Gerken J, Schweer T, Yarza P, Peplies J, Glöckner FO. 2013. The SILVA ribosomal RNA gene database project: improved data processing and Web-based tools. Nucleic Acids Res 41: D590-D596. https://doi.org/10.1093/nar/gks1219.

50. Bolyen E, Rideout JR, Dillon MR, Bokulich NA, Abnet CC, Al-Ghalith GA, Alexander H, Alm EJ, Arumugam M, Asnicar F, Bai Y, Bisanz JE, Bittinger K,
Brejnrod A, Brislawn CJ, Brown CT, Callahan BJ, Caraballo-Rodríguez AM, Chase J, Cope EK, Da Silva R, Diener C, Dorrestein PC, Douglas GM, Durall DM, Duvallet C, Edwardson CF, Ernst M, Estaki M, Fouquier J, Gauglitz JM, Gibbons SM, Gibson DL, Gonzalez A, Gorlick K, Guo J, Hillmann B, Holmes $\mathrm{S}$, Holste $\mathrm{H}$, Huttenhower $\mathrm{C}$, Huttley GA, Janssen S, Jarmusch AK, Jiang L, Kaehler BD, Bin Kang K, Keefe CR, Keim P, Kelley ST, Knights D, Koester I, Kosciolek T, et alet al. 2019. Reproducible, interactive, scalable and extensible microbiome data science using QIIME 2. Nat Biotechnol 37:852-857. https://doi.org/10.1038/s41587-019-0209-9.

51. Zhang J, Kobert K, Flouri T, Stamatakis A. 2014. PEAR: a fast and accurate Illumina Paired-End reAd mergeR. Bioinformatics 30:614-620. https://doi .org/10.1093/bioinformatics/btt593.

52. R Development Core Team. 2010. R: a language and environment for statistical computing. R Foundation for Statistical Computing, Vienna, Austria.

53. Balesdent J, Mariotti A. 1996. Measurement of soil organic matter turnover using ${ }^{13} \mathrm{C}$ natural abundance, $\mathrm{p}$ 83-111. In Boutton TW, Yamasaki S (ed), Mass spectrometry of soils. CRC Press, Boca Raton, FL.

54. McMurdie PJ, Holmes S. 2013. phyloseq: an R package for reproducible interactive analysis and graphics of microbiome census data. PLoS One 8: e61217. https://doi.org/10.1371/journal.pone.0061217.

55. Wickham H. 2009. ggplot2: elegant graphics for data analysis. SpringerVerlag, New York, NY.

56. Wickham H, François R, Henry L, Müller K. 2020. dplyr: a grammar of data manipulation. R package version 1.0.2. https://CRAN.R-project.org/ package $=$ dplyr.

57. Bray JR, Curtis JT. 1957. An ordination of the upland forest communities of southern Wisconsin. Ecol Monogr 27:325-349. https://doi.org/10.2307/ 1942268.

58. Legendre P, Gallagher ED. 2001. Ecologically meaningful transformations for ordination of species data. Oecologia 129:271-280. https://doi.org/10 .1007/s004420100716.

59. Oksanen J, Blanchet FG, Kindt R, Legendre P, Minchin PR, O'Hara RB, Simpson GL, Solymos P, Stevens MHH, Wagner H. 2019. vegan: community ecology package. $R$ package version 2.5-6. https://CRAN.R-project .org/package=vegan.

60. Yilmaz P, Parfrey LW, Yarza P, Gerken J, Pruesse E, Quast C, Schweer T, Peplies J, Ludwig W, Glöckner FO. 2014. The SILVA and "All-species Living Tree Project (LTP)" taxonomic frameworks. Nucleic Acids Res 42: D643-D648. https://doi.org/10.1093/nar/gkt1209. 